\title{
La influencia del Estado en las redes transnacionales de solidaridad. Un acercamiento a la Coordinadora Estatal de Solidaridad con Nicaragua de España (1978-1991)*
}

\section{State Influence on Transnational Solidarity Networks. An Exploration of the Spanish State Coordinating Office of Solidarity with Nicaragua (1978-1991)}

\author{
José Manuel Ágreda Portero** \\ (D) https://orcid.org/0000-0001-8503-0927 \\ Grupo HistAmérica \\ Universidad de Santiago de Compostela, España \\ josemanuel.agreda@rai.usc.es
}

* Trabajo realizado en el marco del Proyecto HAR2016-77828-R, financiado por el Ministerio de Economía, Industria y Competitividad-Agencia Estatal de Investigación (España) y el Fondo Europeo de Desarrollo Regional (FEDER), y en el marco del Grupo de Investigación HistAmérica de la Universidad de Santiago de Compostela, financiado por la Xunta de Galicia (Plan Galego, Consellería de Cultura, Educación e Ordenación Universitaria, 2017 GPC GI-1661).

El presente artículo forma parte de una investigación doctoral más amplia realizada dentro del grupo HistAmérica de la Universidad de Santiago de Compostela, España, y que lleva por título: Internacionalistas, activistas y brigadistas. Las redes transnacionales de solidaridad con la Revolución sandinista desde el Estado español (1978-1991).

** Máster en Historia Contemporánea, Universidad de Zaragoza, España. Estudiante de último año de doctorado, Universidad de Santiago de Compostela España. Líneas de investigación actual: Redes transnacionales de solidaridad con la revolución sandinista en España (1978-1991).

cómo CITAR: Ágreda Portero, J. M. (2020). La influencia del Estado en las redes transnacionales de solidaridad. Un acercamiento a la Coordinadora Estatal de Solidaridad con Nicaragua de España (1978-1992). Secuencia (108), e1847. DoI: https://doi.org/10.18234/secuencia.v0i108.1847 
Resumen: El Frente Sandinista de Liberación Nacional, por medio de personajes conocidos en el mundo occidental como Ernesto Cardenal, armó una red de comités de solidaridad a nivel mundial desde mediados de los años setenta. En España, a partir de 1978, se empezaron a crear comités de solidaridad por todo el territorio a través de Ángel Barrajón, el recién nombrado representante del FSLN para Europa del sur y el Reino Unido. A principios de 1980 se fundó la Coordinadora Estatal de Solidaridad con Nicaragua. Sin embargo, otros comités surgieron de ella como muestra de las diferentes sensibilidades nacionales dentro del Estado español. Los más importantes fueron la Coordinadora Vasca de Comités de Solidaridad Internacionalista y la Coordinadora Catalana de Solidaridad con Nicaragua. Por medio de bibliografía y fuentes documentales, este trabajo busca analizar la importancia de la política nacional y del estado en las redes transnacionales.

Palabras clave: solidaridad; revolución sandinista; España; red transnacional; Estado.

Abstract: Through well-known figures in the Western world such as Ernesto Cardenal, the Sandinista National Liberation Front formed a worldwide network of solidarity committees in the mid-1970s. In Spain, through the newly appointed FSLN representative for southern Europe and the United Kingdom, Ángel Barrajón, solidarity committees began to be created across the country in 1978. In the early 1980s, the State Coordinating Office of Solidarity with Nicaragua was created, while others emerged within it as symbols of the various national sensibilities inside the Spanish state. The most important ones were the Basque Coordinating Committee of Internationalist Solidarity and the Catalan Coordinating Committee of Solidarity with Nicaragua. Through bibliography and documentary sources, this article seeks to address the importance of national and state politics in transnational networks.

Key words: solidarity; sandinista revolution; Spain; transnational network; State. 
Setenta mil estadunidenses, 10000 españoles, 10000 alemanes, 1000 itaS lianos, 500 suizos y varios centenares de ciudadanos de diversos países. Estas son las cifras que Víctor Pozas (2000) aporta sobre la estancia de extranjeros en Nicaragua entre 1979 y 1990 (pp. 282-283). ¿Por qué unas 100000 personas originarias de Estados Unidos, Canadá y Europa occidental pasaron por Managua para trabajar en favor de la revolución sandinista?

El 19 de julio de 1979 el Frente Sandinista de Liberación Nacional (FSLN) derrocó a Anastasio Somoza Debayle, después de un largo periodo de lucha iniciado a principios de los años sesenta, dando inicio a lo que se denomina como revolución sandinista. Entre 1979 y 1990, periodo en el que el FSLN estuvo en el poder, realizó una serie de cambios estructurales. Sus puntos básicos, recogidos en el programa histórico, fueron: economía mixta, reforma agraria y no alineamiento. ${ }^{1}$ A partir de 1981 en Nicaragua hubo un enfrentamiento bélico entre el Ejército Popular Sandinista y grupos guerrilleros contrarrevolucionarios, conocidos como la Contra, apoyados política, militar y económicamente por Ronald Reagan, presidente de Estados Unidos hasta 1989. Este hecho se convirtió en uno de los focos principales de conflicto durante el último periodo de la guerra fría.

Desde 1977 el FSLN creó una red para recabar apoyos, pero esta no se dio en España sino hasta la creación de los primeros comités de solidaridad en 1978. Además de estos 10000 españoles de los que habla Víctor Pozas, hubo muchos otros que se movilizaron desde su territorio doméstico en defensa de la revolución sandinista.

Uno de los objetivos de la red en España fue hacer cambiar las políticas tanto de Adolfo Suárez, presidente español entre 1976 y 1981, contra la dictadura de Anastasio Somoza, como las de Felipe González, presidente español por el Partido Socialista Obrero Español (PSOE) entre 1982 y 1996, en la confrontación entre el gobierno sandinista y Estados Unidos (Blázquez, 2006). Los dos presidentes fueron proclives a la revolución sandinista, vista como moderada, nueva y diferente al modelo soviético, pero ambos sufrieron críticas desde los grupos políticos de izquierda (Roitman, 1985, pp. 116-117).

${ }^{1}$ Aunque el listado del programa histórico y la ideología política del FSLN fue más amplio, estos tres elementos son las principales directrices seguidas durante su gobierno. De forma completa se puede consultar en Departamento de Propaganda y Educación Política del FSLN (1981). El programa histórico del FSLN. Managua: DPEP. 
España, al igual que Nicaragua, sufrió una larga dictadura durante el siglo xx. Tras la muerte del general Franco en 1975 se produjo un proceso que llevó a su modernización. Hubo una transformación política de la dictadura, llamada Transición, que llevó a una monarquía parlamentaria. Esto introdujo a España dentro de los grupos de los países occidentales, a lo que hay que sumar su entrada en la OTAN, en 1981, y en la Comunidad Económica Europea, en 1986. Por otro lado, tras un ajuste durante la crisis de los setenta, la economía española creció, por lo que pasó de ser un país receptor de ayuda a ser donante. En 1988 se creó la Agencia Española de Cooperación Internacional. ${ }^{2}$

El objeto de estudio de este artículo es la Coordinadora Estatal de Solidaridad con Nicaragua (CESN) fundada en Barcelona por todos los comités de solidaridad con Nicaragua existentes en España durante el mes de febrero de 1980. La investigación termina en diciembre de 1991, cuando tuvo lugar en San Sebastián el último Congreso Europeo de Solidaridad con la Revolución Sandinista. A partir de entonces la red se dividió en España. Los que siguieron apoyando al FSLN mantuvieron la CESN hasta finales de la década, aunque también hubo quienes se desligaron de ella y vieron nuevos objetivos en otras luchas.

Las bases bibliográficas para España sobre este tema son escasas, más allá de algunas memorias. ${ }^{3}$ La presente investigación se fundamenta en fuentes primarias. En primer lugar, se han incluido documentos de los diferentes archivos conservados por algunos de los comités que todavía están activos: el Comité de Solidaridad con América Latina de Oviedo, Asturias (CosAL), cuyo legado se encuentra depositado en el Archivo Histórico de Asturias; el Comité de Solidaridad Internacionalista de Zaragoza (csiz), iniciado como Solidaridad con Nicaragua, y la Casa de Nicaragua de Barcelona, custodian ellos mismos su documentación. ${ }^{4}$ Para las conexiones europeas se ha utiliza-

${ }^{2}$ Real Decreto $1527 / 1988$ de 11 de noviembre.

3 Además de unas páginas en la tesis doctoral de Víctor Pozas, existen algunos pequeños estudios por el autor de este artículo (Ágreda, 2016a, 2016b; Ágreda y Helm, 2016). Lo que sí se han publicado han sido memorias de activistas que estuvieron en Nicaragua (Corrales, 2004; Perales, 2005; Romero, 2009). Para Europa occidental hay un poco más de bibliografía; el primer estudio de todos fue el de Kadelbah (2006) sobre las brigadas suizas a Nicaragua. En América Latina, Adrián Jaén (2013) realizó una tesis doctoral sobre la participación de la izquierda costarricense en el derrocamiento de Somoza y Paula Fernández Hellmund (2015) ha estudiado las brigadas realizadas por el Partido Comunista Argentino.

${ }^{4}$ Los archivos del csiz y de la Casa de Nicaragua han sido ordenados y clasificados por el autor. 
do la documentación existente en el International Institute of Social History de Amsterdam. Además de estas fuentes documentales, también se han utilizado una serie de entrevistas realizadas por el autor a diferentes personas que participaron de una u otra manera en la creación de los comités.

Las teorías sobre los movimientos sociales transnacionales se han desarrollado durante los últimos quince años. Para Olesen (2011, p. 7) o Sidney Tarrow (2005) tras la Guerra Fría se creó un mejor clima para el activismo transnacional. Della Porta y Tarrow (2005) establecen características como: el nacimiento de la era de internet y los teléfonos móviles; lenguajes comunes, inglés principalmente, así como la posibilidad de vuelos baratos y el desarrollo de los medios de transporte internacionales. Estos factores ayudarían a la mejor y más rápida conexión entre grupos, pero también entienden que no es algo nuevo y está enraizado en procesos anteriores al fin de la Guerra Fría. ${ }^{5}$ Sin embargo, muchas de las características que estos autores describen se podrían aplicar a la solidaridad con la revolución sandinista. Una de ellas, en la que se va a focalizar este artículo, es la importancia que tiene el estado de origen en las redes transnacionales. Aunque la contención se realiza contra un objetivo externo, es en el territorio doméstico donde se consiguen los recursos para la red y el apoyo político necesario (Stroup, 2011, p. 152).

Para hablar de los activistas transnacionales, Tarrow (2005, p. 29) ha desarrollado el concepto de rooted cosmopolitans. Esto es, "individuos o grupos que movilizan recursos y oportunidades domésticas e internacionales para reivindicaciones de parte de actores externos, contra oponentes externos, o en favor de objetivos que ellos mantienen en común con aliados transnacionales". ${ }^{6}$ Estos activistas transnacionales pertenecen a varios movimientos, en el ámbito doméstico y en el internacional, y se identifican con varios tipos de contención (Della Porta y Tarrow, 2005, pp. 237-238).

Sarah Stroup (2011) realizó un acercamiento al análisis de la relación entre el Estado y las ONG internacionales. Para la autora existen tres puntos para su definición. El primero sería conocer cómo el Estado regula las orga-

${ }^{5}$ Para poder ampliar lo que Della Porta y Tarrow (2005) entienden por la vieja y nueva contención transnacional se puede consultar su libro conjunto, pp. 228-229. Este es un tema que podría resultar apasionante, ¿realmente hay una ruptura entre los procesos contenciosos transnacionales antes y después de 1990? ¿O estamos hablando simplemente de un cambio de objetivo de la contención y nuevos recursos en manos de los activistas? Pero esto queda lejos del objetivo del presente artículo.

${ }^{6}$ Las traducciones de los textos en inglés de la bibliografía han sido realizadas por el autor. 
nizaciones, es decir, si hay facilidad en el registro y exenciones fiscales para quien participa dinerariamente. El segundo mediría las oportunidades políticas, conociendo si las organizaciones no gubernamentales (ONG), por medio de la relación negociada o política contenciosa, son capaces de modificar la postura del estado, en otras palabras, si el Estado permite las presiones, o bien, si está cerrado o es represivo con ellas. El tercer, y último punto, incide en la movilización de recursos materiales. Stroup establece como baremo a medir si el Estado destina importantes cantidades de dinero a la cooperación, qué cantidad de esa ayuda se realiza a través de las oNG y si es fácil o no conseguir ingresos del gobierno.

Recogiendo estas ideas, expuestas de manera escueta, el presente artículo tiene como objetivo advertir cuáles son las principales características de los activistas españoles que militaron en los comités de solidaridad agrupados en la CESN. Es decir, en palabras de Sarah Stroup (2011), "We need a better understanding of those roots" (p. 151). Para ello se ha planteado un estudio evolutivo con base en los cambios producidos dentro de la organización, a las tensiones entre los comités y coordinadoras territoriales que la conforman, además de sus conexiones con otros nodos de la red de solidaridad, como son las conexiones con los comités europeos, las relaciones con el FSLN y los contactos con el estado nicaragüense a través de la embajada.

La organización del texto obedece a un proceso que desarrolla una división lógica de forma muy temprana, el 19 de julio de 1979. Antes de esta fecha la solidaridad se realiza a través de un movimiento guerrillero que utiliza la violencia política para conseguir sus fines, pero posteriormente tiene otras dinámicas diferentes. Desde el triunfo sandinista hasta la creación de la CESN, en 1980, la solidaridad se reorganizó para afrontar los nuevos retos. Entre 1980 y 1984 la red realizó un proceso de ajuste para establecer los medios y modos de relación tanto con la sociedad española, como con el elemento donatario y con otros donantes, en este caso, los comités europeos. A partir de 1984 se inició un mayor flujo tanto de personas, proyectos de cooperación y envío de materiales, por lo que se le ha llamado "el periodo de madurez". La derrota del FSLN en las elecciones del 25 de febrero de 1990 marcó el último gran cambio. Este hecho fue un tremendo mazazo para las ideas y sentimientos de los españoles que, de madrugada, siguieron los acontecimientos pegados a la radio. A partir de entonces ya nada fue lo mismo. 


\section{EL NACIMIENTO DE LA RED EN ESPAÑA, 1978-1979}

El FSLN fue quien impulsó la formación de la red en España. Los primeros comités españoles de solidaridad con Nicaragua fueron creados en Madrid y Barcelona, durante febrero de $1978 .{ }^{7}$ En la capital española, un grupo de nicaragüenses se organizó alrededor de Ángel Barrajón, sacerdote español expulsado de Nicaragua, quien había sido contactado por Ernesto Cardenal para la tarea. Barrajón organizó también la solidaridad en otros países del sur de Europa y el Reino Unido. ${ }^{8}$ El comité de Barcelona se constituyó también en febrero, pero la fundación formal del Comité de Solidaridad de Cataluña con el pueblo de Nicaragua (CosocAN) se realizó el 22 de septiembre de 1979. Su presidente fue el español José María Valverde, aunque el día a día también estuvo gestionado por nicaragüenses residentes en la ciudad. ${ }^{9}$

Hasta el verano de 1979 se crearon en España 17 comités de solidaridad, según la publicación conjunta Nicaragua en Lucha. Durante una reunión acaecida en mayo de 1979 en Madrid, se decidió crear esta revista que fue editada desde Barcelona por CosocAn. En su última página se puede encontrar la lista: Albacete, Gijón, Barcelona, Bilbao, Burgos, Cádiz, Jaén, Madrid, Murcia, Navarra, San Sebastián, Salamanca, Sevilla, Tenerife, Valencia, Zaragoza y Valladolid. ${ }^{10}$

Estos comités fueron creados por tres tipos de activistas: nicaragüenses, latinoamericanos llegados de otros países y españoles. Por medio de Ángel Barrajón, parte de los nicaragüenses asentados en España se organizaron

${ }^{7}$ Para Madrid: Carta de Ángel Barrajón a Vanesa. 7 de agosto de 1978. Archivo privado de Ángel Barrajón, Managua, Nicaragua. Este archivo ha sido posible consultarlo gracias a la gentileza de Eline van Ommen. Para Barcelona: Cosocan. Carta de Cosocan al resto de comités de España. 11 de diciembre de 1978. Caja 11978-1983. Folder 1978. Archivo de la Casa de Nicaragua de Barcelona, España.

${ }^{8}$ Entrevista al señor Ángel Barrajón, realizada por José Manuel Ágreda, vía Skype, 8 de marzo de 2016.

9 José María Valverde era catedrático de estética de la Universidad de Barcelona. Comité de Solidaridad de Catalunya con el pueblo de Nicaragua. Comunicado de creación de CosoCAN. 24 de septiembre de 1978. Arch 01007. Archief Nicaragua Komitee Nederland. Folder 72. International Institute of Social History (en adelante IISH), Amsterdam.

${ }_{10}$ Nicaragua en Lucha, núm. 1, julio-agosto de 1979, p. 46. Fondos Partido Comunista de Aragón. Caja 26560. Internacional: Nicaragua y Noruega (1974-1984). Archivo del Ayuntamiento de Zaragoza, España. 
y promovieron pequeñas acciones de difusión y colecta de fondos. ${ }^{11}$ Este fue el caso del comité de Zaragoza, fundado en octubre de 1979, con un concierto de Carlos Mejía Godoy, residente en la ciudad durante un tiempo, y con el grupo local La Bullonera, en la cripta de la iglesia de Santa Mónica. ${ }^{12}$ Los latinoamericanos exiliados, principalmente argentinos y chilenos, crearon comités junto a españoles, en su mayoría pertenecientes a grupos cristianos, como fue el caso en A Coruña y Pamplona..$^{15}$ Por otro lado, participantes en partidos políticos de izquierdas, a los que el movimiento de solidaridad se acercó para solicitar ayuda, formaron diferentes grupos de apoyo. Por ejemplo, el Movimiento Comunista (MC) creó los primeros comités en zonas como Bilbao o San Sebastián..$^{14}$

Retomando los puntos en los que Stroup basa su análisis, tras la dictadura de Franco, pero sobre todo, a partir de la legalización del partido comunista en 1977, España experimentó un proceso de apertura política que hizo viable la difusión de la lucha sandinista desde la legalidad. La sociedad española pudo, por fin, exponer de manera pública sus posiciones políticas. Además, se retomó el derecho a la reunión, lo que permitió crear estos grupos de solidaridad, aunque en realidad fueron muy informales y no tuvieron ningún tipo de oficialización en la administración española.

La solidaridad se puede concebir de dos formas: intragrupal, para cohesionar grupos; y como un fin, donde dos grupos crean un espacio común (Laitinen y Pessi, 2014, p. 10). ${ }^{15}$ Esta última es la que se desarrolla en este artículo. Pozas (2000) define a los comités como redes de solidaridad popular (pp. 278-279). Un concepto parecido lo podemos encontrar en Waterman (1998, p. 132) pero centrado en la voluntariedad del trabajo. Los beneficiarios

${ }^{11}$ Entrevista con la señora Luz Cuadra, realizada por José Manuel Ágreda, Oviedo, Asturias, 3 y 4 de enero de 2015.

${ }_{12}$ RFo, "Frente sandinista: aislar a Somoza", Andalán, 7, octubre de 1978.

${ }^{13}$ Para el comité de A Coruña: Entrevista con el señor Alfonso Mascuñana, realizada por José Manuel Ágreda, A Coruña, Galicia, 3 de agosto de 2017; Para el comité de Pamplona: Entrevista con la señora Clara López Pérez de Urabayea, realizada por José Manuel Ágreda, Falces, Navarra, 18 de enero de 2019.

${ }^{14}$ Nicaragua en Lucha, núm. 1, julio-agosto de 1979, p. 46. Fondos Partido Comunista de Aragón. Caja 26560. Internacional: Nicaragua y Noruega (1974-1984). Archivo del Ayuntamiento de Zaragoza, España. Allí aparece Iosu Perales, uno de los miembros del Mc en San Sebastián, como la referencia para el comité de la ciudad.

${ }^{15}$ Todas las traducciones del inglés están realizadas por el autor del texto. En algunos casos, para la mejor comprensión de los conceptos o porque en español puede variar ligeramente el significado, se cita también en el idioma original. 
de esta solidaridad pueden ser grupos de personas, organizaciones o Estados, como es el caso de Nicaragua. A grandes rasgos, se llaman comités de solidaridad a grupos de personas que se movilizan en favor de un proceso contencioso generado más allá de los límites de su propio territorio nacional. Pueden apoyar específicamente una lucha, aunque también pueden simpatizar con otras. Quienes participan en ellas lo hacen a título individual, pero pueden pertenecer a otras organizaciones políticas; su trabajo es de carácter voluntario, aunque es posible contar con personas trabajando a tiempo completo, gracias a los fondos conseguidos. Por un lado, estos comités realizan acciones políticas de difusión y publicidad de las luchas que defienden, y, por otro, consiguen ayuda material.

Así definidos, los comités se pueden asemejar a las oNG, pero tienen amplias diferencias. Clifford Bob (2005, pp. 8-9) establece una división entre las redes transnacionales de ayuda (advocacy) y las de solidaridad (solidarity). Las organizaciones de solidaridad (comités), se identifican de manera muy cercana a sus contrapartes a través de relaciones personales asumiendo sin reservas los principios de las organizaciones que defienden. Por otro lado, las organizaciones de ayuda, ONG, están diseñadas para defender una idea mucho más general. Matizando esto, Bob entiende que muchas veces las prácticas de ong como de comités, advocacy y solidarity, se superponen, por lo que en el "fragor de la batalla", para las oNG es difícil separar sus ideales de los defendidos por el grupo donatario.

La red también se organizó a nivel europeo por medio de los contactos entre Ángel Barrajón y Enrique Schmidt, nicaragüense exiliado en Alemania occidental que realizó el trabajo de base para la creación de la red europea. En esta tarea le ayudó su mujer española, María Victoria Urquijo, quien, tras el retorno de Enrique a la lucha en Nicaragua, durante junio de 1979, será la persona encargada de coordinar la solidaridad en Colonia, sustituyendo a su marido, mientras que William Agudelo lo hacía desde Wuppertal. ${ }^{16} \mathrm{El}$ I Encuentro Europeo de comités de solidaridad con Nicaragua tuvo lugar en Madrid entre septiembre y octubre de 1978, donde se reunieron 22 comités de Alemania, Bélgica, España, Francia, Holanda, Puerto Rico, Suecia y Suiza. Allí se establecieron dos objetivos para la solidaridad: conseguir que los res-

${ }_{16}$ Comunicado de Enrique Schmidt y Ángel Barrajón. 19 de junio de 1979. Representación europea del FSLN. Caja 1, 1978-1979. Folder 1979 (1). Archivo de la Casa de Nicaragua de Barcelona, España. 
pectivos gobiernos de dichos países rompieran relaciones diplomáticas con Nicaragua, aislando al régimen y reconociendo como legítimo al gobierno provisional constituido en Costa Rica; $y$, además, recabar apoyo económico para el FSLN. ${ }^{17} \mathrm{~A}$ partir de entonces, las relaciones entre los diferentes comités europeos fueron más fluidas. ${ }^{18}$

Los repertorios de acción que se utilizaron fueron concentraciones, charlas y recogida de fondos. Los actos fueron organizados junto a partidos políticos de izquierdas como el Movimiento Comunista (MC), la Liga Comunista Revolucionaria (LCR) o el Partido Comunista de España (PCE), entre otros. ${ }^{19}$ Los comités se acercaron a este tipo de partidos de ideología similar para tener audiencia. El FSLN dio la consigna de que la solidaridad no podía ser sectaria ni partidaria, así que los comités debían estar abiertos a cualquiera que estuviese dispuesto a apoyar la lucha sandinista. ${ }^{20}$ Sin embargo, a la hora de repartir el dinero recogido hubo problemas con las diferentes tendencias. En noviembre de 1978, Francisco de Asís, miembro de la coordinadora de apoyo en México, uno de los lugares de acopio del dinero y material para la lucha en Nicaragua, estuvo en España. A su vuelta se generó una polémica por la tergiversación de información y el reparto del dinero que se hacía entre las tendencias. ${ }^{21}$ Con la reunificación, las conexiones se centralizaron en Costa Rica, a nombre de Gioconda Belli, en el Zapote. ${ }^{22}$

En resumen, el nacimiento en España de los comités de solidaridad con Nicaragua estuvo muy influenciado por el propio FSLN. Las oportunidades políticas estaban abiertas con la presencia de nicaragüenses, otros latinoamericanos y españoles. Sobre todo, estos dos últimos tenían una alta experiencia en la confrontación social contra dictaduras. La movilización de los recursos

${ }_{17}$ I Encuentro europeo de comités de solidaridad con Nicaragua. 1 de octubre de 1978. Declaración final. Arch 01007 Archief Nicaragua Komitee Nederland. Folder 72. IIHs, Ámsterdam.

${ }_{18}$ Carta del Comité de solidaridad de Madrid a Utrecht. 8 de octubre de 1978. Envío de material. Arch 01007 Archief Nicaragua Komitee Nederland. Folder 72. IIHs, Ámsterdam.

${ }^{19}$ Comunicado de solidaridad con la lucha del pueblo de Nicaragua, 1979. PCE, LCR, MC/ oIC, ORT, PS, PTE, CCOO, CSUT, SU, UGT, USo, IEPALA. Archivo Centro de Documentación de los Movimientos Armados (en adelante Cedema), Valencia, España.

${ }^{20}$ Comunicado del FSLN. A los comités de solidaridad y demás organismos que apoyan la lucha de nuestro pueblo. Mayo de 1979. Cedema, Valencia, España.

${ }^{21}$ Carta de Ángel Barrajón, Allan Lacayo, Adilia, Amaya, Francisco del Teso, María Isabel Hernández del Comité de Madrid. A la Dirección Nacional del fSLN. 10 de diciembre de 1978. Archivo privado de Ángel Barrajón, Managua, Nicaragua.

${ }^{22}$ Comunicado del FSLN. A los comités de solidaridad y demás organismos que apoyan la lucha de nuestro pueblo. Mayo de 1979. Cedema, Valencia, España. 
fue fácil, aunque no cuantiosa, pero hubo problemas en el reparto debido a los desencuentros entre las tres tendencias en que se dividía el FSLN. Tras 20 años de lucha y 40 de dictadura, el 19 de julio de 1979 se da por hecha la derrota de la Guardia Nacional junto con el exilio de Somoza, lo que da inicio a una nueva época para Nicaragua. Un día antes, en Madrid, activistas del comité de solidaridad habían tomado por asalto la embajada nicaragüense. La policía española tuvo que sacarlos a la fuerza. ${ }^{23}$

\section{LA CREACIÓN DE LA COORDINADORA ESTATAL DE SOLIDARIDAD CON NICARAGUA, 1979-1980}

Tras el 19 de julio de 1979, la red de solidaridad sufrió una transformación importante. El objetivo estaba cumplido y ahora se iniciaba un periodo revolucionario en Nicaragua que fue un soplo de esperanza para la izquierda a nivel mundial. A partir de su triunfo, el FSLN intentó establecer una organización piramidal en Europa que, partiendo de coordinadoras en los diferentes países, contactasen con ellos a través del Secretariado europeo. Los comités se quedaron encargados de movilizar recursos de sus propios territorios en aras de mantener la revolución sandinista. La campaña de reconstrucción y la de alfabetización fueron las que marcaron los trabajos que se llevaron a cabo durante este momento.

En un informe, el comité de Madrid se quejaba de que una gran parte de los activistas habían retornado a Nicaragua. ${ }^{24}$ Ángel Barrajón fue uno de ellos. ${ }^{25}$ La primera reunión clave de los comités tuvo lugar entre el 21 y 22 de septiembre en Madrid. Orlando Mayorga, quien asistió por parte del FSLN, expuso los lineamientos para la solidaridad y habló de la coyuntura. Lo importante en esa reunión para el tema de este artículo, fue la división de los comités en zonas. La zona norte abarcaría Galicia, Asturias y Bilbao, y su cabecera estaría en Asturias. La zona centro aglutinaría a Madrid, como la principal, junto con Valladolid y Salamanca. La zona sur organizó a los comi-

${ }^{23}$ J. de las Heras, "Un grupo sandinista ocupó la embajada nicaragüense en Madrid", El País, 19 de julio de 1979. Recuperado de https://elpais.com/diario/1979/07/19/internacional/301183204_850215.html

${ }^{24}$ Comité de Madrid. Informe para la reunión de Herdeke. septiembre de 1979. Caja 4 Varios. Folder Encuentros Internacionales. Archivo de la Casa de Nicaragua de Barcelona, España.

${ }_{25}$ Ángel Barrajón, entrevista citada. 
tés andaluces: Sevilla, Cádiz, Córdoba, Jaén y Huelva, siendo Sevilla el centro coordinador. Por último, la zona este fue formada por Zaragoza, Valencia y Barcelona, quedando esta como referencia. El reparto fue creado sin tener en cuenta las "divisiones naturales" del Estado español. En una España que se estaba reconfigurando territorialmente a través de la creación de las autonomías y los fuertes sentimientos nacionalistas de algunos territorios, esta estructuración estaba fuera de la realidad, por lo que fue bastante efímera. ${ }^{26}$

Otro de los objetivos de la reunión fue preparar el III Encuentro Europeo que se debía celebrar en Herdeke, República Federal Alemana, entre el 28 y el 30 de septiembre. Allí asistió una delegación del Movimiento de Acción Popular Unitaria de El Salvador para pedir solidaridad. En el manifiesto final se señala el apoyo a la lucha del pueblo salvadoreño. Las representantes del FSLN que acudieron a la reunión fueron Mariví Urquijo y Silvia McEwan que leyeron una carta de Enrique Schmidt. Además de explicarles la coyuntura de Nicaragua, les plantearon la nueva estructura de la red. El FSLN había creado la Secretaría de Relaciones Exteriores, dirigida por Doris Tijerino; Silvia McEwan sería la encargada del área de Europa occidental. En el informe que realizó el enviado de Cosocan, en representación de todos los comités del estado, se presentó un organigrama. En cada país debería haber una coordinadora nacional, dividida en zonas y con una persona encargada de establecer los contactos tanto con el secretariado europeo como con la embajada del país. ${ }^{27}$ De esta manera, se reforzaba el carácter vertical de las relaciones.

Los coordinadores de las zonas creadas en septiembre se reunieron en Madrid el día 25 de enero. Asistieron los siguientes representantes: de Euskadi, Arancha Sanjinés; de Asturias, Javier Ramos; de Andalucía, Silvia Padilla; de Madrid, Raúl Elvir, y de Barcelona, Ernesto Fonseca. Además de las cuatro zonas creadas en septiembre, en enero ya había aparecido una más, la de Euskadi. Este fue el primer paso de los comités para estar representados de manera independiente y no por zonas. ${ }^{28}$ El 9 de febrero, se creó en Barcelona

${ }^{26}$ Comités de solidaridad. Informe de la reunión estatal celebrada en Madrid. 22 de septiembre de 1979. Caja 11978-1983. Folder 1979 (1). Archivo de la Casa de Nicaragua de Barcelona, España.

${ }^{27}$ Cosocan. Informe del III Congreso del Movimiento Europeo de Solidaridad con el Pueblo de Nicaragua. 30 de septiembre de 1979. Archivo Centro de Documentación y Solidaridad con América Latina y África (en adelante Cedsala), Valencia, España.

${ }^{28}$ Ernesto Fonseca Fábregas, Cosocan. Circular de la reunión de coordinadoras zonales en el Estado Español. 25 de enero de 1980. Caja 11978-1983. Folder 1980 enero-febrero. Archivo de la Casa de Nicaragua de Barcelona, España. 
la Coordinadora Nacional del Estado español, con los representantes de las cinco zonas. Raúl Elvir fue designado como secretario técnico y encargado de los contactos con el Secretariado Europeo. En la reunión se planteó el problema de la disminución de participantes en los comités. Para solucionarlo se propuso la entrada masiva de españoles. Este hecho supuso que los comités españoles se convirtieron gradualmente en entes más autónomos, eso sí, sin dejar de seguir las consignas de los sandinistas. ${ }^{29}$

El FSLN quiso organizar a los comités como meros recolectores de recursos económicos para trasladarlos a Nicaragua y usarlos en la reconstrucción tras la guerra, pero esto se fue transformado debido a los acontecimientos que tuvieron lugar durante la década. Ya en agosto de 1979 empezaron a llegar proyectos para participar en la Campaña de reconstrucción. ${ }^{30}$ Medicinas, alimentos y ropa escolar fueron los principales bienes que se enviaron a Nicaragua. Los comités recibieron donaciones desinteresadas de ciudadanos. En lo que respecta al Estado, fue de los ayuntamientos de donde consiguieron mayor apoyo. ${ }^{31}$ De hecho, el 10 de octubre tuvo lugar una reunión de los ayuntamientos catalanes presididos por el Partido Socialista Obrero Español (PSOE) en la cual se comprometieron a crear comisiones de ayuda para la reconstrucción de Nicaragua. ${ }^{32}$ También hubo empresas que donaron parte de su producción a los comités, como fue el caso de la empresa de semillas Agrar, que donó al comité de Zaragoza varias toneladas de sus productos. ${ }^{33}$

El principal problema con el que se encontraron los comités fue el de trasladar todos estos insumos a Nicaragua. En los puertos Cádiz, Bilbao y Barcelona se cargaron en barcos con destino al puerto de Corinto, pero esto era muy caro. Desde Barcelona, único lugar del que se tienen documentos, partió el 1 de noviembre el buque Cielo de Génova, con 1072 bultos. Entre

${ }^{29}$ Cosocan. Acta de la primera asamblea general de los coordinadores de la zona de los comités de solidaridad con el pueblo de Nicaragua en el Estado Español. 9 de febrero de 1980. Caja 11978-1983. Folder 1980 enero-febrero. Archivo de la Casa de Nicaragua de Barcelona, España.

${ }^{30}$ Carlos Alemán Ocampo. Carta a Ernesto Cardenal, Ministro de Cultura. 1 de agosto de 1978. Archivo del Informationsbüro Wuppertal, Alemania.

${ }^{31}$ Cosocan. Campaña de ayuda a la reconstrucción de Nicaragua en colaboración con el Ayuntamiento de Barcelona. 9 de septiembre de 1979. Caja 11978-1983. Folder 1979 (1). Archivo de la Casa de Nicaragua de Barcelona, España.

${ }_{32}$ Cosocan. Carta a los alcaldes. 9 de octubre de 1979. Caja 1 1978-1983. Folder 1979 (1). Archivo de la Casa de Nicaragua de Barcelona, España.

${ }_{33}$ Cosocan. Acta de la primera asamblea general de los coordinadores de la zona de los comités de solidaridad con el pueblo de Nicaragua en el Estado Español. 9 de febrero de 1980. Caja 11978-1983. Folder 1980 enero-febrero. Archivo de la Casa de Nicaragua de Barcelona, España. 
ellos, 200 paquetes de crema de Cola Cao, donados por el Comité Ecuatoguineano. ${ }^{34} \mathrm{El} 20$ de febrero partió el buque Belén con 77 bultos. Cáritas patrocinó este segundo envío y también ayudó a enviar paquetes por vía aérea desde Madrid. ${ }^{35}$ Además de esto, el Instituto de Cooperación Iberoamericana, dependiente del gobierno, también ayudó a enviar por esta última vía medicamentos recogidos. ${ }^{36}$

Los comités, exiguos por la salida de nicaragüenses y españoles deseosos de vivir la revolución en Nicaragua, sufrieron una doble reestructuración entre julio de 1979 y febrero de 1980. Por un lado, tuvieron que afrontar una organización de las relaciones a nivel de estado y con el FSLN, ahora como parte del gobierno nicaragüense. Por otro lado, los objetivos ya no fueron contenciosos, sino que se apoyó el proceso revolucionario. Había que enviar bienes y los comités, además de recibir donaciones de la sociedad española, establecieron contactos de colaboración con las instituciones progresistas que en esos momentos se estaban creando en España.

\section{LOS PRIMEROS PASOS DE LA COORDINADORA, 1980-1984}

Las movilizaciones de 1980 fueron principalmente dirigidas hacia la Campaña Nacional de Alfabetización (CNA) desarrollada en Nicaragua. Ya desde 1979 se inició la colecta de material escolar y se crearon manuales didácticos para que fueran usados por los brigadistas. ${ }^{37}$ Nueva Segovia fue la región ni-

${ }^{34}$ Cosocan. Carta a la Secretaría de relaciones exteriores del fSLN. 24 de octubre de 1979. Caja 11978-1983. Folder 1979 (1). Archivo de la Casa de Nicaragua de Barcelona, España.

${ }_{35}$ Cosocan. Carta a Lea Guido, ministra de Bienestar social. 7 de febrero de 1979. Caja 1 1978-1983. Folder 1979 (1). Archivo de la Casa de Nicaragua de Barcelona, España.

${ }^{36}$ Ernesto Fonseca. Carta a la Secretaría de relaciones exteriores del FSLN. 2 de febrero de 1979. Caja 11978-1983. Folder 1980 enero-febrero. Archivo de la Casa de Nicaragua de Barcelona, España.

${ }^{37}$ Para Asturias: Comité de Solidaridad con el Pueblo de Nicaragua "Gaspar García Laviana. Carta a padres y profesores. 1 de diciembre de 1979. Caja 11978-1983. Folder 1979 (1); Para Barcelona: Cosocan. Carta a Ernesto Cardenal. 20 de abril de 1980. Caja 1 1978-1983. Folder 1980 marzo-diciembre. Archivo de la Casa de Nicaragua de Barcelona, España; Para País Vasco: Comité de Solidaridad con Nicaragua de Euskadi. Carta a padres y profesores. 29 de abril de 1980. Archivo Fundación Lazkaoko, Lazkao, España. 
caragüense beneficiada de los materiales enviados por los comités españoles. ${ }^{38}$ Además de enviar material para la CNA hubo españoles que participaron directamente en tierras americanas, incluso, por su cuenta, como Luis Alfredo Lobato Blanco, quien fue a Nicaragua desde su Asturias natal para enrolarse en las brigadas que recorrieron el país. ${ }^{39}$

Dos brigadas provenientes de España, fueron organizadas, la primera, por el Ministerio de Educación y la segunda, curiosamente, por la iglesia austríaca. ${ }^{40}$ Aunque pueda resultar sorprendente que la curia católica de Austria organizase una brigada de maestros españoles a Nicaragua, ${ }^{41}$ esta es una prueba de las características que ya se habían apuntado anteriormente: las conexiones culturales pueden suponer un acicate para las relaciones solidarias. El español, como lengua vehicular de la red transnacional de solidaridad con la revolución sandinista, y todas aquellas que involucran a países de América Latina, excepto Brasil, supone una ventaja comparativa para los internacionalistas y activistas españoles en ese territorio.

Durante 1980 se publicaron las últimas revistas unitarias. En Nicaragua en Lucha, números 3 y 4, se puede apreciar cómo los comités han ido aumentando. ${ }^{42} \mathrm{~A}$ los anteriormente mencionados hay que añadir los de las ciudades de Zamora y Córdoba, así como el de la región de Cantabria, con lo que suman un total de veinte. Estos nuevos comités son el producto directo de las gestiones de los miembros más comprometidos de la red.

En 1981 bajó la intensidad del trabajo solidario en España, de hecho, se observa escasez de documentación en los archivos consultados. En Barcelona, por ejemplo, había desaparecido Cosocan y, a mediados de 1982, José María Valverde junto a otras personas, entre las que se encontraba el famoso escritor

38 Cosocan. Carta a la Junta Departamental de Nueva Segovia. 10 de mayo de 1980. Caja 11978-1983. Folder 1980 marzo-diciembre. Archivo de la Casa de Nicaragua de Barcelona, España.

39 Entrevista al señor Luis Alfredo Lobato Blanco, realizada por José Manuel Ágreda Portero. Managua, Nicaragua, 17 de agosto de 1980.

40 El embajador español Pedro de Arístegui realizó un acto en agosto de 1980 donde las dos brigadas se dieron el relevo. Sin autor, "Alfabetizadores españoles: 50 vienen y 50 se van", La Prensa, 30 de agosto de 1980. El recorte de esta noticia fue encontrado en el archivo privado de Nuria Roig, Palafrugell, Gerona, España.

${ }^{41}$ Existe una publicación interna con un informe completo de la brigada: Acción "Maestros españoles en Nicaragua”. Archivo privado de Nuria Roig, Palafrugell, Gerona, España.

${ }^{42}$ Nicaragua en Lucha, núm. 3, febrero de 1980 y núm. 4, sin fecha. Fondos Partido Comunista de Aragón. Caja 26560, Internacional: Nicaragua y Noruega (1974-1984). Archivo del Ayuntamiento de Zaragoza, España. 
Manuel Vázquez Montalbán, fundaron la Casa de Nicaragua. ${ }^{43}$ Asociaciones como esta debían ceñirse a la Ley de asociaciones de 1964, una normativa franquista. La mayoría de los comités eran simplemente un grupo de personas que se reunían con una idea común y no se legalizaban. Por ejemplo, el Comité de Solidaridad de Zaragoza lo hizo, con la misma ley de 1964, a principios de 1985, casi siete años después de su fundación. ${ }^{44}$ Como se puede comprobar, hasta mitad de la década de los ochenta, las organizaciones no se plantean una formalización administrativa. Cada comité de cada ciudad, por medio de contactos personales con los partidos políticos, obtiene apoyo y difusión para sus acciones y campañas.

Pronto llegaron los nubarrones sobre la revolución sandinista. Ronald Reagan fue nombrado presidente de Estados Unidos de América en enero de 1981. Aunque las críticas al proceso revolucionario ya habían iniciado el año anterior, su política de financiamiento de la Contra se convirtió en el principal objetivo de confrontación con los sandinistas y, por ende, con la solidaridad durante la década de los ochenta. En los meses de marzo y abril de 1981 se sucedieron reuniones para crear, a instancias del FSLN, un frente antiintervencionista junto a la guerrilla salvadoreña y guatemalteca. ${ }^{45}$ Los acuerdos tomados en el v y vi Congreso Europeo de comités de solidaridad con Nicaragua, celebrados en París y Ginebra respectivamente, pusieron en marcha lo que se denominó Movimiento Anti Intervencionista (MAI). ${ }^{46}$

La principal acción llevada a cabo fue una Caravana Anti Intervencionista que recorrió Europa occidental, en mayo de 1982. En ella participaron: representantes del FSLN, FLMN y FP 31; el grupo de música Pancasan; un representante del Secretariado Europeo, del Movimiento por la paz y otro del movimiento antiintervención de Estados Unidos. Todos juntos visitaron tre-

${ }^{43}$ Casa de Nicaragua. Acta. 29 de junio de 1982. Caja 1 1978-1983. Folder 1982. Archivo de la Casa de Nicaragua de Barcelona, España; Casa de Nicaragua. Estatutos. 1982. Cedsala, Valencia, España.

${ }^{44}$ Comité de Solidaridad con Nicaragua de Zaragoza. Registro de la asociación. 15 de febrero de 1982. Archivo del Comité de Solidaridad Internacionalista de Zaragoza, España.

${ }_{45}$ Klaas Wellinga. Convocatoria para el encuentro europeo de comités de París. 29 de marzo de 1981. Arch 02528. Informationsbüro Wuppertal. IISH, Ámsterdam.

${ }^{46}$ Para el Congreso de París: Secretariado Europeo. (Actas del v Congreso Europeo de Comités de Solidaridad con Nicaragua. Abril de 1980. Arch 02528 Informationsbüro Wuppertal. IISH, Ámsterdam; Para el Congreso de Ginebra: Secretariado Europeo. Actas del vi Congreso Europeo de Ginebra. noviembre de 1981. Archivo Comité de Solidaridad con América Latina (en adelante Cosal), Asturias, España. 
ce países europeos durante seis semanas. En España hubo actos en Bilbao, Madrid, Zaragoza y Barcelona. El 1 de junio se realizó en Estrasburgo una manifestación delante de la sede del Parlamento Europeo. Por cada país que pasaba la caravana, los comités publicaron una declaración conjunta preparada por el Secretariado Europeo. ${ }^{47}$

Hasta el 19 de julio de 1979 el modelo boomerang de Keck y Skkink (1998, p. 12) fue aplicable a la lucha contra Somoza, pero posteriormente ya no pudo ser aplicable al no existir una acción contenciosa contra el Estado nicaragüense. Los objetivos de la solidaridad transcendieron los niveles de apoyo material y sufrió lo que los teóricos llaman Scale Shift (Tarrow, 2005, pp. 120-121). Esto significa que la contención se muda del plano nacional, como fue la lucha contra Somoza, a una escala global. En 1981 la revolución sandinista y toda Centroamérica se convirtieron en uno de los principales puntos calientes de la guerra fría. Además, uno de los objetivos de los comités europeos fue constituir una institución supranacional, como el Parlamento Europeo. Por otro lado, se forjaron alianzas de dos tipos: con otros movimientos importantes, como es el caso del Movimiento por la paz, y con los activistas de Estados Unidos.

La política nacional se entremezclaba con la actividad solidaria. En noviembre de 1982 se celebró el VII Congreso Europeo en Rotterdam aun cuando estaba previsto celebrarse en Bilbao. La razón fue que los Komites Internazionalistak, como se llamaron en el País Vasco, estaban formados entre otras organizaciones por miembros de Herri Batasuna. Este partido político tenía conexiones con la organización terrorista ETA y los sandinistas no consideraron apropiada la celebración del congreso. La CESN llevó una propuesta para pedir explicaciones. ${ }^{48}$ Por otro lado, desde la entrada de España en la oTAN en 1981 se crearon comités antioTAN por todo el estado. Estos reclamaban un referéndum sobre la participación del país en esta organización militar. El PSOE ganó las elecciones nacionales con esta promesa que no cumplió hasta 1986. En ese periodo, el Movimiento por la Paz, ya asentado en Europa occidental y Estados Unidos, fue creciendo en España, con lo que los comités de

${ }^{47}$ Hans Langenberg. Carta a los coordinadores de la caravana MAI. 21 de abril de 1982. Arch 02528. Informationsbüro Wuppertal. IIsH, Ámsterdam.

${ }^{48}$ Coordinadora Vasca de solidaridad con Nicaragua. Acta. 11 de septiembre de 1982; Coordinadora Estatal de Solidaridad con Nicaragua. Acta. 30 de octubre de 1982. CosAl, Asturias, España. 
solidaridad encontraron en él un apoyo para la difusión y organización por todo el estado. ${ }^{49}$

Entre 1980 y 1983 se establecieron las bases para la creación de los marcos compartidos entre los sandinistas y los activistas españoles. Tanto el Triunfo del 19 de julio como la cNA pusieron en primera plana la revolución sandinista. A partir de 1981 y durante el inicio de la guerra de la Contra, el FSLN estimuló el desarrollo de la red solidaria como medio de defensa política e influencia en los gobiernos de Europa occidental. Muchos activistas desearon compartir ese nuevo sueño y se prestaron a defenderlo, Xavier Corrales (2004) explicó sus sentimientos en una frase: "Éramos jóvenes e íbamos de vacaciones a una revolución que considerábamos también nuestra” (p. 18).

\section{LA MADUREZ DE LA SOLIDARIDAD, 1984-1988}

El XI Congreso Europeo, celebrado en Zaragoza durante los días 10 y 12 de febrero de 1984, fue clave para la autonomía de los comités. Estos decidieron organizarse por sí mismos. El Secretariado Europeo, nombrado por el FSLN para canalizar las relaciones con todos los comités europeos y ratificado por estos durante el II Congreso Europeo de Utrech de abril de 1979, fue destituido. ${ }^{50} \mathrm{~A}$ lo largo estos años, los comités habían organizado conexiones propias con el FSLN y diferentes organizaciones en Nicaragua, por lo que ya no era necesario centralizar los canales de contacto. Las redes de solidaridad no son un mero transmisor de la voluntad de la parte donataria, en este caso, aunque la posición del FSLN siempre fue preeminente, buscaron su propia dirección y una organización autónoma de su parte de la red, eso sí, siempre siguiendo las directrices que llegaban de los sandinistas.

El potencial movilizador de la CESN fue creciendo gracias a la organización de las coordinadoras en los diferentes territorios. Existían algunas desde principios de los ochenta, como la andaluza o la vasca, pero fue en esta segunda mitad de la década cuando su presencia se generalizó. La Coordi-

${ }^{49}$ Nelson Jaramillo y Liduine Zampolle. Carta de la organización Movimiento Europeo y Norteamericano por la Paz. 8 de febrero de 1983. Arch 02528. Informationsbüro Wuppertal. IISH, Ámsterdam.

${ }^{50}$ IX Congreso Europeo de Comités de Solidaridad con Nicaragua. Actas. 10 a 12 de febrero de 1984. Fondos del Partido Comunista de Aragón. Caja 26560. Internacional: Nicaragua y Noruega (1974-1984). Archivo del Ayuntamiento de Zaragoza, España. 
nadora Catalana de Solidaridad con Nicaragua (CCSN), una de las más importantes dentro de la CESN, se fundó en marzo de 1984 a instancias de la Casa de Nicaragua..$^{51}$ El objetivo fue "constituir un mecanismo permanente de coordinación de las acciones a favor de Nicaragua". ${ }^{2}$ Para ello se reunió a 27 organizaciones que, en su mayoría, no eran comités de solidaridad sino sindicatos, partidos políticos o facultades de las universidades de Cataluña. El Comité de solidaridad con Nicaragua de Madrid recibió críticas por su gestión de la CESN, lo que llevó a la dimisión de sus representantes en 1986, a partir de entonces fue la ccsN quien coordinó los comités.

Otro camino diferente tomó la solidaridad vasca, influida por su sentimiento independentista frente al estado español. Los desencuentros y el deseo de organizarse de manera autónoma llevaron a su separación a inicios de 1985 (García, 2019, p. 207). Dentro de las propias organizaciones vascas surgió también una corriente que quiso estrechar más su vinculación con los partidos y organizaciones independentistas. Por ello, en 1987 la coordinadora vasca se escindió y apareció una nueva organización: Askapena (Valencia, 2011, p. 89). Las dos corrientes escindidas se diferenciaban básicamente en su concepción de la solidaridad. Mientras que los Komites Internazionalistak buscaban apoyar principalmente las luchas de otros pueblos por su liberación, eso sí, sin olvidar los deseos independentistas propios, Askapena surgió de la estrategia de la izquierda independentista vasca para conformar sus propios movimientos sociales y con una concepción de la solidaridad de ida y vuelta, es decir, además de ofrecer su apoyo para las luchas ajenas, también buscaron obtener reconocimiento de sus contrapartes como demandantes de solidaridad y así conseguir su propio objetivo: la independencia de Euskadi. ${ }^{53}$

La invasión de Granada fue un aliciente para el internacionalismo en Centroamérica. Nicaragua tuvo que afrontar una avalancha de extranjeros (García, 2019, p. 207); por ello, alentaron, en octubre de 1983, la creación de

${ }^{51}$ Casa de Nicaragua. Acta de constitución de la ccsN. 16 de marzo de 1982. Caja 2 19841987. Folder creación de la Coordinadora Catalana de Solidaridad con Nicaragua. Archivo de la Casa de Nicaragua de Barcelona, España.

${ }^{52}$ Casa de Nicaragua. Comunicado. Febrero de 1982. Caja 1984-1987. Folder creación de la Coordinadora Catalana de Solidaridad con Nicaragua. Archivo de la Casa de Nicaragua de Barcelona, España.

53 Entrevista al señor Jesús Valencia, realizada por José Manuel Ágreda, Vitoria, España, 3 de marzo de 2019. 
uniones de residentes de cada nacionalidad. ${ }^{54}$ Los españoles se organizaron en torno a la Unión de Residentes "Gaspar García Laviana". En un primer momento se pusieron al frente Miguel Ángel Martínez e Isaías Barreñada, dos jóvenes internacionalistas que el Comité Central del Partido Comunista de España había nombrado como sus representantes en Nicaragua. El objetivo que se pretendió inicialmente fue convertirse en la representación de las coordinadoras nacionales en Nicaragua. De esta forma, la información y las directrices del FSLN llegarían de forma más directa. ${ }^{55}$ Pero la CESN no quiso intermediarios, pues los activistas de la solidaridad con Nicaragua querían un contacto directo con los sandinistas. El Departamento de Relaciones Internacionales, que hasta entonces era quien gestionaba las relaciones solidarias, se vio desbordado; por este motivo designó al Comité Nicaragüense de Solidaridad con los Pueblos (CNSP), creado en 1980, para gestionar lo referente a contactos, información, brigadas y consignas con los comités de Europa occidental. ${ }^{56}$ En 1987, debido a la crisis económica y al proceso de compactación del estado sandinista, el CNSP se unió con el resto de comités sandinistas dependientes del DRI, creando un solo organismo llamado Comité Nicaragüense de Amistad, Solidaridad y Paz (CNASP).

Las relaciones entre los comités españoles y Nicaragua estuvieron marcadas por la presencia de Pablo Otero, de origen brasileño y gallego. En 1986, ante el fallo en las conexiones entre la Unión de Residentes y la CESN, tuvo el encargo desde el CNSP de intentar organizar las relaciones con España. Para ello, fundó en Nicaragua el Comité Ambrosio Mogorrón (САM), en honor a un internacionalista vasco muerto por las minas dejadas por la Contra en San Juan de Bocay. Presentándose como un comité más a la CESN, en vez de ser el eslabón entre CNSP y la solidaridad española, fue aceptado. Los comités querían contactos directos y no intermediarios pero, al estar el cNsp de acuer-

${ }^{54}$ Comité Nicaragüense de Solidaridad con los pueblos. (2 de noviembre de 1983). Internacionalistas cooperantes de Europa, Estados Unidos, Canadá y América Latina en Nicaragua anunciaron en conferencia de prensa la creación de las Uniones de Extranjeros Residentes en Nicaragua. IHNCA-AH-C_87_5-14. Fondo Barricada. Comité Nicaragüense de Solidaridad con los Pueblos. Instituto de Historia de Nicaragua y Centroamérica-Archivo Histórico (en adelante IHNCA-AH), Managua, Nicaragua.

${ }^{55}$ Entrevista al señor Isaías Barreñada, realizada por José Manuel Ágreda, Madrid, España, 3 de marzo de 2019; Entrevista al señor Miguel Ángel Martínez, realizada por José Manuel Ágreda, Madrid, España, 3 de marzo de 2019.

${ }^{56}$ Francisco de Asís, presidente del CNSP. Carta a los comités de solidaridad de Europa occidental. 20 de agosto de 1984. CosAl, Asturias, España. 
do más la posición privilegiada del CAM, tuvieron que tenerlo en cuenta. La labor principal de Pablo Otero y sus colaboradores fue recibir a las brigadas y organizarles el trabajo, además, desde el CAM se enviaba información directa a los comités de lo que acontecía en Nicaragua. ${ }^{57}$

La información es una de las claves en las redes transnacionales (Keck y Sikkink, 1998, pp. 18, 21 y 28). Además de las publicaciones realizadas por el CAM, el FSLN difundió la publicación de Barricada Internacional más allá de sus fronteras. En 1986, el propio Pablo Otero desembarcó en Barcelona con el proyecto de imprimir desde allí Barricada Internacional para toda Europa. También circuló durante un tiempo la versión en alemán de esta publicación, desde Bonn, y en inglés, desde Londres. ${ }^{58}$ La difusión de la información fue clave para los sandinistas pero sobre todo para los activistas, quienes la necesitaban para poder presentar ante la sociedad su versión del conflicto.

Tras el embargo económico de Estados Unidos en junio de 1985, Daniel Ortega dio inicio a una campaña internacional para mitigar los efectos: Nicaragua debe sobrevivir (Peace, 2012, p. 165). Esta campaña duró varios años y abarcaba todo tipo de materiales, desde medicinas hasta material escolar. Uno de los problemas con los que se encontraron los comités fue cómo hacer llegar los insumos a Nicaragua, ya que los costes del transporte marítimo eran muy caros. Para ello, desde el consulado de Barcelona se creó la Oficina de cooperación con Nicaragua, en octubre de 1987. El trabajo realizado fue muy importante, ya que no sólo enviaba los materiales recaudados por los comités, sino también por las empresas y todo aquel que quisiera enviar ayuda material a Nicaragua. ${ }^{59}$ La segunda gran campaña llevada a cabo a nivel mundial tuvo su origen en junio de 1986, cuando el Congreso norteamericano aprobó la ayuda de 100000000 de dólares para la Contra. ${ }^{60}$ La red de solidaridad se movilizó de nuevo con el objetivo de conseguir 100000000 de pesetas, pero solamente se consiguió enviar 35000000 de pesetas desde España. ${ }^{61}$ Las

${ }^{57}$ Entrevista al señor Pablo Otero, realizada por José Manuel Ágreda, San Pere de Ribas, España, 6 de junio de 2015.

${ }^{58}$ Señor Pablo Otero, entrevista citada.

${ }^{59}$ Oficina de Cooperación con Nicaragua. Díptico. 1988. Caja 2, Solidaridad 2. Folder Estado nicaragüense. Archivo de José María Valverde, España.

${ }^{60}$ F. G. Basterra, "Estados Unidos alimenta con otros 100 millones de dólares la guerra de la 'contra', El País, 27 de junio de 1986. Recuperado de https:/elpais.com/diario/1986/06/27/ internacional/520207211_850215.html

${ }^{61}$ СіDов. Planificación de la campaña "100 millones para Nicaragua". 10 de octubre de 1986. Archivo privado de Nuria Roig, Palafrugell, Gerona, España. 
desgracias no vienen solas, pues en octubre de 1988 un huracán de categoría 4 asoló la costa caribeña de Nicaragua y la solidaridad se volcó de nuevo en conseguir recursos. En total se recaudaron 52 024. 48 de pesetas entre octubre y enero de $1989 .{ }^{62}$

Una de las características generales de los movimientos sociales es establecer alianzas que puedan resultar beneficiosas, ya sea por motivos materiales o ideológicos. El Movimiento por la Paz y el Desarme europeo fue, como se ha explicado anteriormente, el principal aliado de los comités de solidaridad con Nicaragua. De hecho, la CESN sólo realizó brigadas propias entre 1983 y 1985. Las brigadas más importantes enviadas desde la CESN se realizaron entre 1986 y 1989, en apoyo a los dos proyectos de la Coordinadora Estatal de Organizaciones Pacifistas (CEOP). Estos consistían en la construcción de casas para el reasentamiento de desplazados de guerra en los términos de Las Latas y El Salto, cerca de Jinotega. Los comités que llevaron a cabo estos proyectos fueron los que menos posibilidad de movilización de recursos tenían, ya que tanto la coordinadora vasca como la catalana tenían sus propios proyectos (Ágreda, 2019). Para el resto de países de habla no hispana era indispensable que entre los brigadistas hubiera traductores: La cantidad mínima eran diez personas y dos más con conocimientos técnicos. La brigada debía contar con un traductor, financiamiento para el proyecto y gastos de estadía. ${ }^{63}$

En este periodo, de manera general, España ya se había modernizado y también lo hizo en el ámbito de la solidaridad internacional. Desde mediados de los años ochenta surgieron ONG que consiguieron captar fondos de las diferentes administraciones para proyectos en el exterior. Las coordinadoras de comités estatales de Nicaragua y El Salvador confluyeron en la creación de la ONG Entrepueblos. La CCSN tuvo la iniciativa; una vez aprobados los estatutos fueron depositados en el registro el día 14 de diciembre de $1987 .{ }^{64}$

1988 fue un año de aniversario para la solidaridad en España, pues se cumplía una década del inicio masivo de comités de solidaridad, por ello en

${ }^{62}$ Banco Hispano Americano. Ingreso en cuenta Nicaragua debe Sobrevivir. 23 de enero de 1989. Caja 3 1988-1991. Folder 1988 Huracán Juana. Archivo de la Casa de Nicaragua de Barcelona, España.

${ }^{63}$ Sin autor (11 de marzo de 1989). Se prepara recepción de brigadas. Barricada Internacional (287), 17. Archivo del Comité de Solidaridad Internacionalista de Zaragoza, España.

${ }^{64}$ Comisión coordinadora de la creación de Entrepueblos. Carta a los comités y coordinadoras. 23 de diciembre de 1987. Archivo del Comité de Solidaridad Internacionalista de Zaragoza, España. 
diciembre del mismo año se celebró el I Encuentro de la Solidaridad de las Naciones y las Regiones del Estado Español. Además, al celebrarse en Asturias, se conmemoraba también el décimo aniversario de la muerte de Gaspar García Laviana. 340 activistas debatieron durante dos días sobre la solidaridad. También asistieron como contrapartes: Patricia Elvir, del CNASP, Madres de la Plaza de Mayo, de Argentina, y una nieta "rescatada del horror", así como dirigentes guatemaltecos, peruanos, colombianos y palestinos: ${ }^{65}$ "Se presentaron 18 ponencias que nos permitieron debatir un conjunto amplio de temas que resumen en conjunto las preocupaciones del Movimiento Internacionalista hoy: las ongs, el papel de las instituciones, la participación de los cristianos en el proceso de liberación, etc. destacando especialmente el V Centenario, del que se presentaron cuatro ponencias."

\section{LA CRISIS DE LA SOLIDARIDAD, 1989-1991}

En 1989 se celebró el décimo aniversario de la revolución sandinista. Diferentes comités realizaron actos por toda España, incluso algunos combinados con el de la revolución cubana, como en Sevilla. ${ }^{66} \mathrm{La}$ CCSN publicó en formato de lujo un libro y una revista donde explicaba estos diez años de revolución y cómo Nicaragua resistió a la agresión estadunidense. ${ }^{67}$

Durante el verano de ese año, viajaron al proyecto de El Salto las últimas brigadas con 65 personas. En la publicidad que la CESN creó para informar sobre la participación en las brigadas de 1989 se pueden observar cambios en la denominación de los comités y los territorios donde se ubicaban: Colectivo de solidaridad con Centroamérica, Madrid; Cosal, Murcia; Cedsala, Valencia; Asociación extremeña de solidaridad con los pueblos de América Latina; Coordinadora Catalana de solidaritat amb Nicaragua; Comité de Solidaridad con Nicaragua, Zaragoza; Cosal, Oviedo; Comité de Solidaridad con Nicaragua, Gran Canaria; CosAl, Talavera de la Reina; CosAl, Palencia; Cosal, Salamanca; Comité de solidaritat amb Nicaragua, Ciutadella; Colec-

${ }^{65}$ Cosal Asturias. 1er Alcuentru de la Solidarida. Documentos. Diciembre 1988. Archivo del Comité de Solidaridad Internacionalista de Zaragoza, España.

${ }^{66}$ Comité de solidaridad con Centroamérica y Chile, Sevilla, 1989. Tríptico: La Revolución en América Latina. Archivo privado de Nuria Roig, Palafrugell, Gerona, España.

${ }^{67}$ Coordinadora Catalana de Solidaridad con Nicaragua. Nicaragua 10 anys de sobirania. 1989. Caja 1 Solidaridad 1. Folder CCSN. Archivo de José María Valverde, España. 
tivo de Solidaridad con Nicaragua, Palma de Mallorca; Cosal, Vigo; Coordinadora andaluza de solidaridad con Centroamérica, Granada (Ágreda, 2019, p. 253). La tendencia de los comités fue dedicarse a zonas geográficas concretas, ya que los Cosal son el tipo de comité que más se repite; solamente Zaragoza, que lo cambiará en 1991, los comités de Baleares (Ciutadella y Palma de Mallorca), Canarias y Cataluña siguieron denominándose con el término "solidaridad con Nicaragua". Además, es importante apuntar cómo la coordinadora catalana se unió a las brigadas comunes del Estado. La razón hay que buscarla en la creación de la oNG Entrepueblos, que asumió los proyectos con Nicaragua anteriormente desarrollados por la coordinadora. La irrupción de las ONG en España tuvo el efecto de disminuir la capacidad de los comités.

"Los sandinistas ganarían las elecciones en España", esta frase fue espetada por Virgilio Godoy en una entrevista concedida a la publicación española Diario 16. La Unión Nacional Opositora, rival político del FSLN, estaba molesta porque Felipe González había declarado que este iba a ganar las elecciones del 25 de febrero. ${ }^{68}$ El presidente se equivocó y con él, las personas que habían participado en la campaña que se desarrolló en España a favor del Daniel Ortega. Tanto en Madrid como en Barcelona se crearon grupos de apoyo. ${ }^{69} \mathrm{Su}$ objetivo fue unificar los esfuerzos para mostrar a la sociedad española que en Nicaragua se estaban realizando unas elecciones limpias y con todas las garantías por parte del FsLN. Desde Managua llegaron directrices para contrarrestar las críticas realizadas. ${ }^{70}$

Iosu Perales (1990) estuvo en Managua como observador internacional y describió así su angustia cuando recibió la noticia de que el FSLN había perdido los comicios: "De repente nos sentimos cósmicamente solos y la presencia de los demás en la misma sala del televisor no podía darnos el consuelo que necesitábamos" (p. 5). Hubo manifestaciones privadas y públicas de apoyo a la revolución. ${ }^{71}$ La consigna fue gobernar desde abajo y mantener

${ }^{68}$ R. Orozco, "Godoy: Los sandinistas sólo ganarán a Violeta si la mandan asesinar", Diario 16, 14 de febrero de 1990.

${ }^{69}$ Para Barcelona: José María Valverde. Caraga a Patricia Braniff Duffau. 8 de noviembre de 1989. Caja 1 Solidaridad 1. Folder Casa de Nicaragua 1; Para Madrid: Documento (sin fecha definida). Nicaragua. 10 años de Revolución. Caja1 Solidaridad 1. Folder Elecciones 1990. Archivo de José María Valverde, España.

${ }^{70}$ Sin autor. Preguntas y respuestas sobre el proceso electoral. 9 de julio de 1989. Caja 1 Solidaridad 1. Folder Elecciones 1990. Archivo de José María Valverde, España.

${ }^{71}$ José María Valverde. Carta a Daniel Ortega. 27 de febrero de 1990. Caja 10. Correspondencia. Folder 1990-2002; Comunicado: "Seguim amb el Frente Sandinista", El País, edición 
los logros de la revolución, pero la guerra y la desmovilización de la Contra seguía estando en una posición central. Antes del traspaso de poderes a Violeta Chamorro se realizaron concentraciones ante la embajada y consulado estadunidense; para el día 25 de abril, fecha exacta del cambio de gobierno, se prepararon manifestaciones en diferentes puntos del país exigiendo el desarme de la Contra. ${ }^{72}$

A partir de la derrota electoral, el FSLN tuvo que reformar sus estructuras. Desapareció el CNASP y la conexión, a partir de 1990, se realizó directamente a través del DRI, ahora liderado por Henry Ruíz, hasta entonces ministro de cooperación. ${ }^{73}$ Por otro lado, las contrapartes nicaragüenses debían ser las organizaciones de masas sandinistas y los ayuntamientos que todavía quedaron en manos del FSLN. Las brigadas de la CESN ya no fueron dependientes de la CEOP; los brigadistas que a mediados de los ochenta se habían iniciado en la red y ahora residían permanentemente en Nicaragua, tuvieron la capacidad de organizarlas por sí mismos. Ocotal fue el destino para 1990, por medio de la recién creada ONG Popol Na dirigida por Mónica Baltodano. El proyecto consistió en levantar un polideportivo en la ciudad. 40 brigadistas llegaron ese verano a una Nicaragua convulsa por los enfrentamientos de los sandinistas con las políticas del estado. ${ }^{74}$

La consternación fue tal que el II Encuentro de la Solidaridad a nivel estatal, a realizarse durante la primavera de 1990, se postergó hasta noviembre del mismo año. Esta reunión supuso una continuación de la realizada en Asturias durante 1988. Al acto, que tuvo lugar en Salamanca, acudieron los comités que trabajaban con Centroamérica (Nicaragua, El Salvador y Guatemala). Allí se oyeron críticas aunque en su resolución final no se reflejasen: "si un error de ayer fue el 'acriticismo, el seguidismo' en el (inexistente) diálogo con el FSLN, si también lo fue la falta de valentía en el señalamiento a los

Barcelona, 11 de marzo de 1990. Caja 1 Solidaridad con Nicaragua. Folder Casa de Nicaragua 1. Archivo de José María Valverde, España.

${ }^{72}$ Asociación de amistad hispano nicaragüense Rubén Darío. Carta a José María Valverde. 5 de abril de 1990. Caja 10 Correspondencia. Folder 1990-2002. Archivo de José María Valverde, España.

${ }^{73}$ Asociación de amistad hispano nicaragüense Rubén Darío. Carta a José María Valverde. 5 de abril de 1990. Caja 10 Correspondencia. Folder 1990-2002. Archivo de José María Valverde, España.

${ }^{74}$ Entrevista al señor Joaquín Alfonso, realizada por José Manuel Ágreda, Zaragoza, España, 27 de diciembre de 2014. 
sandinistas de abusos y corruptelas, si fue un error nuestra poca voluntad de analizar con ojos propios la realidad [...], de eso debemos hablar". ${ }^{75}$

Ante la derrota de las elecciones en Nicaragua, la situación en El Salvador y Guatemala, la caída del bloque soviético, la nueva campaña contra Cuba, la posibilidad de una guerra en el Golfo Pérsico y, en definitiva, el desmantelamiento de la situación geopolítica de la Guerra Fría, los comités tuvieron que reorganizar sus objetivos e ideales. Se pasó de apoyar luchas concretas a visiones más generales y globales, a la búsqueda de una justicia social: "Seguir dinamizando tanto a los movimientos sociales (feministas, trabajadores, ecopacifistas, cristianos...) como a los sectores juveniles y alternativos de manera que la solidaridad pueda ser un punto de encuentro común donde reivindicar una sociedad más justa y solidaria." ${ }^{76}$

Un mes después tuvo lugar el XVI Encuentro Europeo de Comités de Solidaridad con Nicaragua, celebrado en Viena. El representante enviado por el FSLN, Hernán Estrada, presentó un documento titulado "Elementos para la elaboración de una nueva estrategia de trabajo del movimiento de la solidaridad con Nicaragua". ${ }^{77}$ Las directrices se basaron en apoyar a las organizaciones de todo tipo propias del frente, seguir con la ayuda material y apoyo a los medios de comunicación sandinistas. Las diferentes representaciones de los países plantearon sus críticas al documento. Para los comités no había nada nuevo: a la solidaridad se le pedía un mayor esfuerzo económico y reducción del esfuerzo político. Sobre todo, el principal malestar fue la falta de información; los comités pedían que el FSLN enviara interpretaciones y posturas políticas que no apareciesen también en los medios. ${ }^{78}$

El último acontecimiento del que se va a hacer mención es el encuentro europeo realizado en San Sebastián, País Vasco. A finales de 1991 hubo una intensa actividad del FSLN con la solidaridad. En octubre se celebró en Managua el I Encuentro de Héroes y Mártires de la Solidaridad Internacional, como se denominarían a partir de entonces los encuentros internacionales de la solida-

75 Comité de Solidaridad con Nicaragua de Zaragoza. Notas para la reunión de Salamanca. Octubre de 1990. Archivo del Comité de Solidaridad Internacionalista de Zaragoza, España.

${ }^{76}$ Sin autor. Resolución final del II Encuentro de Solidaridad con Centroamérica. 4 de noviembre de 1990. Cedsala, Valencia, España.

${ }_{77}$ Departamento de Relaciones Internacionales del FSLN. Elementos para la elaboración de una nueva estrategia de trabajo del movimiento de la solidaridad con Nicaragua. 26 de octubre de 1990. Archivo del Comité de Solidaridad Internacionalista de Zaragoza, España.

${ }^{78}$ XVI Encuentro Europeo de Comités de Solidaridad con Nicaragua, Viena. Actas. 1 de noviembre de 1990. Archivo del Comité de Solidaridad Internacionalista de Zaragoza, España. 
ridad en Nicaragua. ${ }^{79}$ En noviembre tuvo lugar el Encuentro de Hermanamientos-FSLN. ${ }^{80}$ Del 6 al 8 de diciembre, los Komites Internazionalistak y Askapena, de manera conjunta, organizaron el Encuentro europeo en San Sebastián.

A Euskadi acudieron principalmente organizaciones del Estado español pero también llegaron delegaciones de Italia, Noruega, Holanda, Suiza, Francia, Grecia e Inglaterra. El principal ausente fue Alemania que, tras la caída del muro de Berlín y el inicio del proceso de reunificación, dedicó todos sus esfuerzos a los asuntos internos. ${ }^{81}$ Durante el encuentro hubo dos posturas enfrentadas: aquellos que querían seguir demostrando una solidaridad incondicional al fSLN, como la Asociación de Amistad Hispano-Nicaragüense Rubén Darío, la Asociación Catalana de Brigadistas con Nicaragua y los representantes de los comités ingleses. Aquellos que buscaban una mayor autonomía presentaron una posición condicionada al liderazgo del FSLN, sus convicciones revolucionarias y, sobre todo, a los progresos prácticos que fueran capaces de conseguir. ${ }^{82}$

En el fondo se ha planteado la discusión, no siempre franca y abierta, de si la solidaridad tiene que estar bajo la dirección del FSLN o por el contrario desde su soberanía debe acordar sus apoyos y solidaridades con el FSLN. Los primeros parecen decir ¡Dirección Nacional ordene!, los segundos decimos que canalicemos la solidaridad con el partido sandinista cuando estemos de acuerdo, a la vez que defendamos otros canales (CST, ATC, FNT... proyectos comunales, etc.). ${ }^{83}$

La situación terminó con la aprobación de la siguiente resolución que fue la principal fuente de disputa. Se llegó a un acuerdo puntual en San Sebastián, pero las diferencias estuvieron ya marcadas a partir de entonces: "1.- Rea-

${ }^{79}$ Henry Ruíz. Discurso Inaugural de I Encuentro de Héroes y Mártires de la solidaridad internacional. 18 de octubre de 1991. Archivo Komite Internazionalistak de Donosti, España.

${ }^{80}$ DRI FSLN. Fax del Acta del Encuentro de Hermanamientos-FSLN. 27 de noviembre de 1991. Archivo Komite Internazionalistak de Donosti, España.

${ }^{81}$ Komité Internazionalistak de Donosti. Breve balance de los encuentros europeos de solidaridad con Nicaragua. Diciembre de 1991. Archivo Komite Internazionalistak de Donosti, España.

${ }^{82}$ Komité Internazionalistak de Donosti. Aportaciones al texto "Sobre la crisis de la solidaridad”. Diciembre de 1991. Archivo Komite Internazionalistak de Donosti, España.

${ }^{83}$ Komité Internazionalistak de Donosti. Breve balance de los encuentros europeos de solidaridad con Nicaragua. Diciembre de 1991. Archivo Komite Internazionalistak de Donosti, España. 
firmar nuestra solidaridad con la revolución nicaragüense y de modo particular con el Frente Sandinista de Liberación Nacional y con las organizaciones sindicales, comunales y sectoriales que forman parte del proyecto sandinista." Como se puede apreciar, el FSLN fue considerado como una "parte del proyecto sandinista".

\section{CONCLUSIONES}

La red de solidaridad transnacional en la que participaron los activistas españoles estuvo articulada en tres nodos de unión que mantenían relaciones constantes para su coordinación. El primer nodo fue la Coordinadora Estatal, donde se aglutinaron todos los comités creados a favor de la lucha sandinista. Desde este punto se trazan dos conexiones: hacia Nicaragua y hacia los comités europeos. La nicaragüense es la más importante, ya que fue el territorio receptor de solidaridad. Los comités españoles tuvieron conexión directa con el FSLN aunque estuvo mediatizada por los españoles residentes quienes hacían de puente informativo habitual. Por otro lado, la conexión con los comités europeos sirvió para establecer unos objetivos comunes y poder realizar acciones contra organizaciones supranacionales, como la Comunidad Económica Europea. Además, fue otro de los canales de conexión con el FsLN ya que a los congresos siempre acudía una representación que informaba directamente de la coyuntura y las consignas pertinentes.

Los parámetros que Sarah Stroup propone no definen por completo las redes de solidaridad. Según la autora, para que una red transnacional sea fructífera el Estado debe permitir y regular la creación de organizaciones de este tipo. A finales de los setenta y principios de los ochenta, en España había una regulación heredada de la ley de 1964, desde la dictadura franquista. Tampoco había una conciencia sobre la necesidad de oficializarse; por ello, los comités se formaron de manera poco estructurada: un grupo de personas con una idea común simplemente se organizaban entre ellas y se autoerigían en "comités de...". Sin embargo, a mediados de los ochenta surgió la conciencia sobre la necesidad de registrarse y poner por escrito unos estatutos.

El segundo punto sobre el que basó su análisis fue el de las oportunidades políticas. Los casi 40 años de dictadura franquista fueron una dura escuela para los movimientos sociales y políticos en España. Tras la muerte del dictador Francisco Franco, gran parte de la población estaba politizada, así 
que participó en el proceso de transición a la democracia parlamentaria. Parte de estos activistas percibieron que los cambios más profundos que ellos anhelaban estaban cerrados y vieron la posibilidad de alcanzarlos a través de las revoluciones latinoamericanas. Por otro lado, con el devenir de los años y la modernización tanto de España como en lo referente a movimientos sociales, el crecimiento de un movimiento global como fue el Movimiento por la Paz el Desarme y la Libertad se utilizó para desarrollar las conexiones y difundir los relatos propios de la solidaridad.

En lo que se refiere a la movilización de los recursos, en sus inicios fueron obtenidos principalmente a través de pequeñas donaciones individuales, además de relaciones personales, partidos políticos, sindicatos y las pocas organizaciones no gubernamentales de carácter católico progresista, que también aportaron recursos al movimiento de solidaridad. A través de ellos consiguieron llegar a las instancias de poder, en su mayor parte ayuntamientos. A mediados de la década de los ochenta, la cooperación española fue desarrollándose y aumentando. La red de solidaridad fue modificándose al mismo ritmo y creando las estructuras necesarias para participar de ese proceso interno.

Sarah Stroup se basa principalmente en la teoría de la movilización de recursos para analizar el concepto de rooted cosmopolitans, algo necesario, pero se olvida de otros factores importantes para su comprensión, como el ideológico y el político así como de las conexiones personales, aunque, ciertamente, estas son más difícilmente medibles. La intención de este artículo no es la de negar los postulados de los investigadores mencionados; al contrario, el objetivo es complementar sus ideas con el caso de las relaciones solidarias entre la red popular española y la revolución sandinista. La solidaridad durante los años ochenta podría considerarse como el eslabón donde se producen los cambios desde el internacionalismo obrero hacia una idea de justicia global.

En lo que respecta a las características de la red de solidaridad con la revolución sandinista en España, se puede establecer que el FSLN fue quien creó la red y buscó los contactos necesarios para que aumentase. Para el caso específico de la revolución sandinista, la antropóloga argentina Paula Fernández Hellmund (2015) plantea una modificación de la teoría del don. A la teoría clásica de "dar, recibir y devolver" ella añade la acción de "solicitar". El FSLN, el donatario, sería el receptor de la solidaridad aunque su posición no fue pasiva sino activa, ya que solicitó y organizó la solidaridad. Por otro lado, los grupos de activistas, es decir, el donante, corresponderían a los españoles 
que ofrecen solidaridad. En el espacio intermedio entre los dos, donantes-donatarios, es donde se establecen los marcos compartidos de movilización.

Ese control de la red por parte del FSLN poco a poco fue diluyéndose por un deseo de autonomía de los comités. Esto se debió a la incorporación masiva de españoles, en su mayoría, militantes de partidos políticos de izquierda radical. A lo largo de la década de los ochenta los comités, creados para una lucha individual como la sandinista, fueron agrupándose y constituyendo comités internacionalistas o CoSAL. La CESN quiso controlar directamente el flujo de contactos con el FSLN, pero tuvo que aceptar la intermediación de los internacionalistas españoles del Comité Ambrosio Mogorrón. En 1984, en la ciudad española de Zaragoza, se consumó, durante el IX Congreso Europeo, la destitución del secretariado europeo nombrado por el FsLN. Es cierto, como plantea Clifford Bob, que los comités de solidaridad tienen una mayor implicación en los marcos compartidos con el elemento donatario, pero no es una identificación completa.

En España había poca tradición de movimientos de solidaridad, si se compara con otros países del bloque occidental. La lucha contra la dictadura de Franco absorbió todos los esfuerzos políticos. Incluso recibieron ayuda de comités de solidaridad a favor de los presos políticos del régimen franquista creados en otras regiones de Europa y en América Latina. Así como en otros países tuvieron fuerza los movimientos contra las dictaduras chilena o argentina, en España, la revolución sandinista fue el acontecimiento que marcó el inicio de los movimientos de solidaridad con América Latina. Todo ello ayudado por la presencia de una gran colonia de exiliados y estudiantes del otro lado del océano.

La relación cultural y, en concreto, el idioma español, supone una ventaja comparativa a la hora de establecer contactos y relaciones solidarias entre España y Latinoamérica. Prueba de ello fue que los obispos católicos austríacos buscasen en España universitarios para su brigada de alfabetización en 1980 o que el DRI estableciese la cuota de dos traductores para realizar una brigada a Nicaragua. Lo comités de solidaridad españoles estaban exentos. Los estadunidenses constituyeron el mayor número de activistas en Nicaragua debido a su tradición de movilización política y a la cantidad de recursos, pero también a su cercanía geográfica. Mientras, España, en el segundo lugar, estaba al nivel de un país mucho más desarrollado y con mayor tradición en estos movimientos transnacionales, como Alemania. Otros de los factores a su favor fueron la facilidad de los viajes, con conexión directa por avión des- 
de Madrid, y los aspectos culturales compartidos con España, como es una lengua común.

La última característica de la red fueron las diferenciaciones territoriales y nacionales dentro del propio Estado español. Durante la década de los ochenta, el País Vasco incrementó el desarrollo de la ideología independentista. Un ejemplo de ello fue la separación de la CESN a mitad de la década de los ochenta y la propia fractura del movimiento vasco de solidaridad en 1987. A los congresos europeos asistía una representación por país, pero desde España llegaban tres: la de la CESN, la de los comités internacionalistas vascos y Askapena, por los independentistas.

En definitiva, como se ha planteado al principio del artículo, los nodos de la red de movimientos de solidaridad transnacional obtienen las características de su propio territorio donante. Los activistas nacionales que participan en ella tienen el bagaje político y contencioso propio de su estado. Este hecho influye en las conexiones con otros nodos e incluso, con la parte donataria. El concepto de rooted cosmopolitans nos permite ver más allá del conflicto social de un país y trazar las implicaciones a nivel global. Pero para ello hay que superar las visiones basadas en un solo elemento, como son los recursos, y obtener un mapa holístico con características políticas, sociales y culturales.

\section{LISTA DE REFERENCIAS}

Ágreda Portero, J. M. (2016a). Movimientos de apoyo a la revolución nicaragüense: una posibilidad de análisis. El archivo del Partido Comunista de Aragón (España). En S. Rinke (Ed.). Entre espacios. Historia latinoamericana en el contexto global (pp. 650-666). Berlín: Universidad Libre de Berlín.

Ágreda Portero, J. M. (2016b). Un acercamiento al Comité de Solidaridad con Nicaragua de Zaragoza, España (1978-1990). Nuevo Mundo Mundos Nuevos. DoI: https:// doi.org/10.4000/nuevomundo.69639

Ágreda Portero, J. M. y Helm, C. (2016). Solidaridad con la Revolución Sandinista. Comparativa de redes nacionales: los casos de la República Federal de Alemania y España. Naveg@merica. Revista electrónica Editada Por La Asociación Española De Americanistas 17. Recuperado de http://revistas.um.es/navegamerica/article/ view/271921

Ágreda Portero, J. M. (2019). Redes transnacionales de solidaridad política. Las brigadas de solidaridad española con la Revolución sandinista (1979-1990). En C. Al- 
quézar, et al. (eds.), Naciones en conflicto. Zaragoza: Universidad de Zaragoza. DoI: https://doi.org/10.26754/uz.978-84-16723-74-4

Blázquez, B. (2006). La proyección de un líder político: Felipe González y Nicaragua 19781996. Sevilla: Centro de Estudios Andaluces.

Bob, C. (2005). The Marketing of Rebellion. Insurgents, Media, and International Activism. Nueva York: Cambridge University Press.

Corrales, X. (2004). Nicaragua: un paseo entre volcanes. Valencia: Universidad Politécnica de Valencia.

Della Porta, D. y Tarrow, S. (2005). Transnational Protest and Global Activism. Rowman and Littlefield: Nueva York.

Fernández, P. (2015). Nicaragua debe sobrevivir. La solidaridad de la militancia comunista argentina con la Revolución sandinista (1979-1990). Buenos Aires: Ediciones Imago Mundi.

García, T. (2019). Lava y ceniza. La Revolución sandinista y el volcán de la solidaridad vasca. Donostia: Txertoa.

Jaén, A. (2013). Movimientos sociales y solidaridad política: la participación de la izquierda costarricense en la Revolución sandinista. (Tesis de doctorado inédita). Flacso, San José de Costa Rica.

Kadelbach, T. (2006). Les Brigadistes suisses au Nicaragua (1982-1990). Friburgo: Universidad de Friburgo.

Keck, M. E. y Sikkink, K. (1998). Activists Beyond Borders. Advocacy Networks in International Politics. Nueva York: Cornnell University Press.

Laitinen, A. y Pessi, A. B. (2014). Solidarity: Theory and Practice. Nueva York: Lexinton Books.

Olesen, T. (2011). Power and Transnational Activism. Nueva York: Routledge.

Peace, R. (2012). A Call to Conscience. The Anti-Contra War Campaing. Boston: University of Massachusetts Press

Perales, I. (coord.) (1990). Elecciones en Nicaragua. Madrid: Revolución.

Perales, I. (2005). Los buenos años. Nicaragua en la memoria. Barcelona: Icaria.

Pozas Pardo, V. (2000). Nicaragua (1979-1990). Actor singular del pragmatismo y protagonismo de la Revolución sandinista en la escena internacional. (Tesis de doctorado inédita). EHU, Bilbao.

Roitman, M. (1985). La política del PSOE en América Latina. Madrid: Editorial Revolución.

Romero, A. (2009) Las brigadas de solidaridad con Nicaragua de los años ochenta: una expresión de internacionalismo en las postrimerías de la Guerra Fría. En J. 
Gascón, El turismo en la cooperación internacional, de las brigadas internacionales al turismo solidario (pp. 122-131). Barcelona: Icaria Antrazyt.

Stroup, S. (2011). National Origin and Transnational Activism. En T. Olesen. Power and Transnational Activism. Nueva York: Routledge.

Tarrow, S. (2005). The New Transnational Activism. Cambridge: Cambridge University Press.

Valencia, J. (2011). La ternura de los pueblos. Euskal Herria Internacionalista. Navarra: Txalaparta.

Waterman, P. (1998). Globalization, Social Movements and the New Internationalism. Londres: Mansell Publishing Limited.

\section{OTRAS FUENTES}

\section{Archivos}

Archivo de José María Valverde, España.

Archivo de la Casa de Nicaragua de Barcelona, España.

Archivo del Ayuntamiento de Zaragoza, España.

Archivo del Comité de Solidaridad Internacionalista de Zaragoza, España.

Archivo del Informationsbüro Wuppertal, Alemania.

Archivo Fundación Lazkaoko, Lazkao, España.

Archivo Komite Internazionalistak de Donosti, España.

Archivo privado de Ángel Barrajón, Managua, Nicaragua.

Archivo privado de Nuria Roig, Palafrugell, Gerona, España.

Cedema Centro de Documentación de los Movimientos Armados, Valencia, España.

Cedsala Centro de Documentación y Solidaridad con América Latina y África, Valencia, España.

Cosal Comité de Solidaridad con América Latina, Asturias, España.

IHNCA Instituto de Historia de Nicaragua y Centroamérica, Managua, Nicaragua.

IISH International Institute of Social History, Ámsterdam. 